\title{
Postharvest changes in the phenolic profile of watercress induced by post- packaging irradiation and modified atmosphere packaging
}

\author{
José Pinela $^{\mathrm{a}, \mathrm{b}}$, Lillian Barros ${ }^{\mathrm{a}}$, João C.M. Barreira ${ }^{\mathrm{a}}$, Ana Maria Carvalho ${ }^{\mathrm{a}}$, \\ M. Beatriz P.P. Oliveira ${ }^{\mathrm{b}}$, Celestino Santos-Buelga ${ }^{\mathrm{c}}$, Isabel C.F.R. Ferreira, ${ }^{\mathrm{a}, *}$ \\ a Centro de Investigação de Montanha (CIMO), Instituto Politécnico de Bragança, Campus de Santa Apolónia, 5300-253 Bragança, Portugal \\ ${ }^{\mathrm{b}}$ REQUIMTE/LAQV, Faculdade de Farmácia, Universidade do Porto, Rua Jorge Viterbo Ferreira, $n^{\circ} 228,4050-313$ Porto, Portugal \\ ${ }^{c}$ Grupo de Investigación en Polifenoles (GIP-USAL), Universidad de Salamanca, Facultad de Farmacia, Campus Miguel de Unamuno, E-37007 Salamanca, Spain
}

\section{A R T I C L E I N F O}

\section{Keywords:}

Nasturtium officinale

Phenolic compounds

HPLC-DAD-ESI/MS

Modified atmosphere packaging

Post-packaging irradiation

Refrigerated storage

\begin{abstract}
A B S T R A C T
The effects of $\gamma$-ray irradiation and modified atmosphere packaging (MAP) on watercress (Nasturtium officinale R. Br.) phenolic compounds were evaluated after 7-day storage at $4{ }^{\circ} \mathrm{C}$. Irradiation doses of 1,2 and $5 \mathrm{kGy}$ were tested, as well as vacuum-packaging and MAP enriched with $100 \% \mathrm{~N}_{2}$ and $\mathrm{Ar}$. A non-irradiated, air-packaged control was included in all experiments. $p$-Coumaric acid was the most abundant compound in fresh watercress, followed by quercetin-3-O-sophoroside and isorhamnetin- $O$-hydroxyferuloylhexoside- $O$-hexoside. Four kaempferol glycoside derivatives were identified for the first time in this species. In general, flavonoids predominated over phenolic acids. Samples stored under vacuum and irradiated at $2 \mathrm{kGy}$ revealed lower phenolic levels. Arenriched MAP and control conditions preserved the initial phenolic content. The $5 \mathrm{kGy}$ dose also maintained concentrations of flavonoids and total phenolic compounds, but increased the phenolic acids content. Additionally, flavonoids were found strongly correlated to $\mathrm{DPPH}^{*}$ scavenging activity and $\beta$-carotene bleaching inhibition capacity.
\end{abstract}

\section{Introduction}

Fresh-cut vegetables have become more popular in consumers' market baskets due to their convenience, nutritional and flavour properties, and health benefits (Baselice, Colantuoni, Lass, Nardone, \& Stasi, 2017). In addition, their consumption is highly recommended by most food-based dietary guidelines due to the high contents of vitamins and bioactive compounds such as ascorbic acid (vitamin C), tocopherols (vitamin E), carotenoids and phenolic compounds (Kacjan Marsić, Sircelj, \& Kastelec, 2010; Vilela et al., 2014). Moreover, an inverse association between the intake of these foods and the risk of degenerative diseases caused by oxidative stress has been attributed to the high levels of these antioxidants (Boeing et al., 2012).

The global interest in minimally processed packaged foods promoted the exponential growth of this industrial sector, which is showing positive figures and innovation in product quality and safety attributes (Baselice et al., 2017; Ma, Zhang, Bhandari, \& Gao, 2017). In the past few years, watercress (Nasturtium officinale $\mathrm{R}$. Br.) has become popular as a fresh-cut product due to the sharp, peppery and slightly tangy taste. This fast-growing semi-aquatic plant of the Brassicaceae family is frequently classed as a superfood or functional food due to the high level of bioactive phytochemicals and health-promoting effects (Spínola, Pinto, \& Castilho, 2016; Zeb, 2015). Watercress supplementation in diet has been linked to a reduced risk of cancer in healthy adults, via decreased damage to DNA and possible modulation of antioxidant status (Boyd et al., 2006; Gill et al., 2007), and might be useful in modulating breast cancer progression and disease recurrence (Ravasco, João, Jorge et al., 2015; Ravasco, João, Rowland et al. 2015). However, like most fresh-cut vegetables, watercress has a reduced shelflife of approximately 7 days (Silveira, Araneda, Hinojosa, \& Escalona, 2014).

After harvest, fresh vegetables begin to lose quality due to various chemical and/or enzymatic reactions (Sandhya, 2010). In addition, the damage caused by the cutting and processing operations promotes a faster deterioration of the fresh-cut vegetables than the unprocessed ones (Francis et al., 2012). The wound-induced stress activates plant defence mechanisms involved in the synthesis and/or degradation of antioxidants, such as phenolic compounds (Han et al., 2016), whose accumulation in wounded tissues has been associated with an increase in antioxidant activity (Fernando Reyes, Emilio Villarreal, \& CisnerosZevallos, 2007). Therefore, as the popularity of watercress increases, there is a need to understand how the phenolic profile of this

\footnotetext{
* Corresponding author.

E-mail address: iferreira@ipb.pt (I.C.F.R. Ferreira).
} 
cruciferous vegetable is affected by different postharvest treatments and how it evolves during storage.

The fresh-cut sector is constantly evolving and innovating in order to enhance the quality and safety of the marketed products. For this reason, the impact of non-thermal preservation technologies on quality attributes of fresh vegetables has been widely investigated so as to find suitable postharvest treatments for shelf-life extension and microbiological safety assurance, as well as to replace the communally used chemical sanitizers (Pinela \& Ferreira, 2017). In this way, the consumers' expectations for convenient foods with fresh-like properties, free of chemical residues, and treated in a more sustainable way may be attended. These requisites can be achieved by using post-packaging irradiation and modified atmosphere packaging (MAP) in combination with refrigerated storage. $\gamma$-Ray irradiation is a clean technology capable of reducing the microbial load, control insect pests, and delay ripening and senescence on different plants (Barkai-Golan \& Follett, 2017). This physical treatment can be applied to packaged foods, thus preventing the occurrence of recontaminations during storage. However, suitable doses for shelf-life extension need to be established for each food commodity, always aiming to have a minimum impact on quality parameters. On the other hand, MAP consists of changing the headspace gas composition inside the package with the aim of reducing physiological and oxidation processes, as well as the microbial grow (Pinela, Barreira, Barros, Antonio, et al., 2016; Pinela, Barreira, Barros, Cabo Verde, Antonio, et al., 2016b; Sandhya, 2010; Silveira et al., 2014). Using these non-thermal preservation techniques in combination with refrigerated storage, the food shelf-life can be extended, postharvest losses can be reduced, and new markets can be reached.

In previous studies, we evaluated how important quality attributes of watercress (i.e., colour, $\mathrm{pH}$, proximate composition, hydrophilic (free sugars and organic acids including ascorbic acid) and lipophilic (fatty acids and tocopherols) compounds, and antioxidant activity) are affected by post-packaging $\gamma$-ray irradiation (Pinela, Barreira, Barros, Cabo Verde, Antonio, et al., 2016a) and MAP (Pinela, Barreira, Barros, Antonio, et al., 2016). However, the impact of these postharvest treatments on individual phenolic compounds was not investigated and, as far as we know, only the effects of a 10-day storage period at $3 \pm 1{ }^{\circ} \mathrm{C}$ were studied until now (Santos, Oliveira, Ibáñez, \& Herrero, 2014). Therefore, the present study was carried out to assess the effects of postharvest treatments of irradiation $(0,1,2$ and $5 \mathrm{kGy})$ and MAP (vacuum, $100 \% \mathrm{~N}_{2}$ and $100 \% \mathrm{Ar}$ ) on the phenolic profile of fresh-cut watercress stored at $4{ }^{\circ} \mathrm{C}$ for 7 days. A possible correlation between phenolic compounds and antioxidant activity was also investigated.

\section{Materials and methods}

\subsection{Standards and reagents}

HPLC-grade acetonitrile was purchased from Fisher Scientific (Lisbon, Portugal). Formic acid was purchased from Prolabo (VWR International, France). The phenolic compound standards (ferulic, sinapic, $p$-coumaric and caffeic acids, and kaempferol-3-O-rutinoside, quercetin-3-O-rutinoside, and quercetin-3-O-glucoside) were purchased from Extrasynthese (Genay, France). All other chemicals were of analytical grade and were purchased from common sources. Water was treated in a Milli-Q water purification system (Millipore, model A10, Billerica, MA, USA).

\subsection{Sampling, samples preparation and postharvest preservation treatments}

Watercress (Nasturtium officinale R. Br.) specimens were wild harvested in February 2014 in a stream located in the civil parish of Calvelhe, Bragança municipality, in Portugal, considering local consumers' sites and preferences (Carvalho \& Morales, 2013). The use of wild-harvested watercress allowed control over the postharvest time of the samples. On the same day, undamaged watercress parts (tender stems and leaves) were hand-picked, rinsed in tap water, and a portion was immediately analysed (non-stored control). The remaining fresh material was packaged in $11.5 \mathrm{~cm} \times 15 \mathrm{~cm}$ sterilized bags $(0.5 \mathrm{~L}$ headspace volume) of low-density polyethylene ( $63 \mu \mathrm{m}$ thickness) and subjected to different postharvest preservation treatments as previously described (Pinela, Barreira, Barros, Antonio, et al., 2016; Pinela, Barreira, Barros, Cabo Verde, Antonio, et al., 2016a). In brief, 70 bags containing $20 \mathrm{~g}$ of watercress were prepared and then divided into 7 groups (10 bags per treatment): i) three groups were $\gamma$-ray irradiated at 1,2 and $5 \mathrm{kGy}$ (predicted doses) in a cobalt-60 experimental chamber (Precisa 22, Graviner Manufacturing Company Ltd., UK) located in the Centre for Nuclear Sciences and Technologies (C2TN) in Bobadela, Portugal; ii) one group was a non-irradiated ( $0 \mathrm{kGy})$ control in conventional atmosphere (air) included in all the experiments; iii) another group was vacuum-packaged; and iv) two groups were packaged in modified atmosphere enriched with $100 \% \mathrm{~N}_{2}$ and Ar. The evolution of the headspace gas composition in each bag was monitored as previously reported (Pinela, Barreira, Barros, Antonio, et al., 2016). All packaged samples were stored at $4^{\circ} \mathrm{C}$ for 7 days.

\subsection{Preparation of extracts}

After storage, all watercress samples were immediately lyophilised (FreeZone 4.5, Labconco, Kansas City, MO, USA), reduced to a fine powder (20 mesh), and subjected to a solid-liquid extraction as previously described by the authors (Pinela, Barreira, Barros, Antonio, et al., 2016; Pinela, Barreira, Barros, Cabo Verde, Antonio, et al., 2016a). In brief, the dry powder ( $1 \mathrm{~g}$ ) was stirred with a methanol:water mixture $(80: 20, \mathrm{v} / \mathrm{v} ; 50 \mathrm{ml})$ for $1 \mathrm{~h}$ at room temperature. The supernatant was then filtered and the residue was re-extracted with a same portion of solvent. After concentration of the extracts under reduced pressure (rotary evaporator Büchi R-210, Flawil, Switzerland), the aqueous phase was lyophilized to obtain dry extracts.

\subsection{Analysis of phenolic compounds by HPLC-DAD-ESI/MS}

After preparation, the dry extracts $(\sim 10 \mathrm{mg})$ were dissolved in a methanol:water mixture $(20: 80 \mathrm{v} / \mathrm{v})$, filtered through $0.22 \mu \mathrm{m}$ disposable LC filter disks and then analysed in a Dionex Ultimate 3000 UPLC system (Thermo Scientific, San Jose, CA, USA) equipped with a diode array detector (DAD, 280 and $370 \mathrm{~nm}$ were the selected wavelengths) coupled to an electrospray ionization mass detector (ESI-MS) (ThermoFinnigan, San Jose, CA, USA). The system and analytical procedures were previously described by Bessada, Barreira, Barros, Ferreira and Oliveira (2016).

MS detection was performed in negative mode, using a Linear Ion Trap LTQ XL mass spectrometer (Thermo Finnigan, San Jose, CA, USA) equipped with an ESI source. Nitrogen served as the sheath gas (50 psi); the system was operated with a spray voltage of $5 \mathrm{kV}$, a source temperature of $325^{\circ} \mathrm{C}$, a capillary voltage of $-20 \mathrm{~V}$. The tube lens offset was kept at a voltage of $-66 \mathrm{~V}$. The full scan covered the mass range from $\mathrm{m} / \mathrm{z} 100$ to 1500 . The collision energy used was 35 (arbitrary units). Data acquisition was carried out with Xcalibur ${ }^{\circledR}$ data system (Thermo Finnigan, San Jose, CA, USA).

The phenolic compounds were identified based on their chromatographic behaviour, UV-vis and mass spectra by comparison with standard compounds (when available) and by using data reported in the literature. For quantitative analysis, a calibration curve for each available phenolic standard was constructed based on the UV signal. For the identified phenolic compounds for which a commercial standard was not available, the quantification was performed through the calibration curve of the most similar available standard. The results were expressed in $\mathrm{g}$ per $\mathrm{kg}$ of extract. 


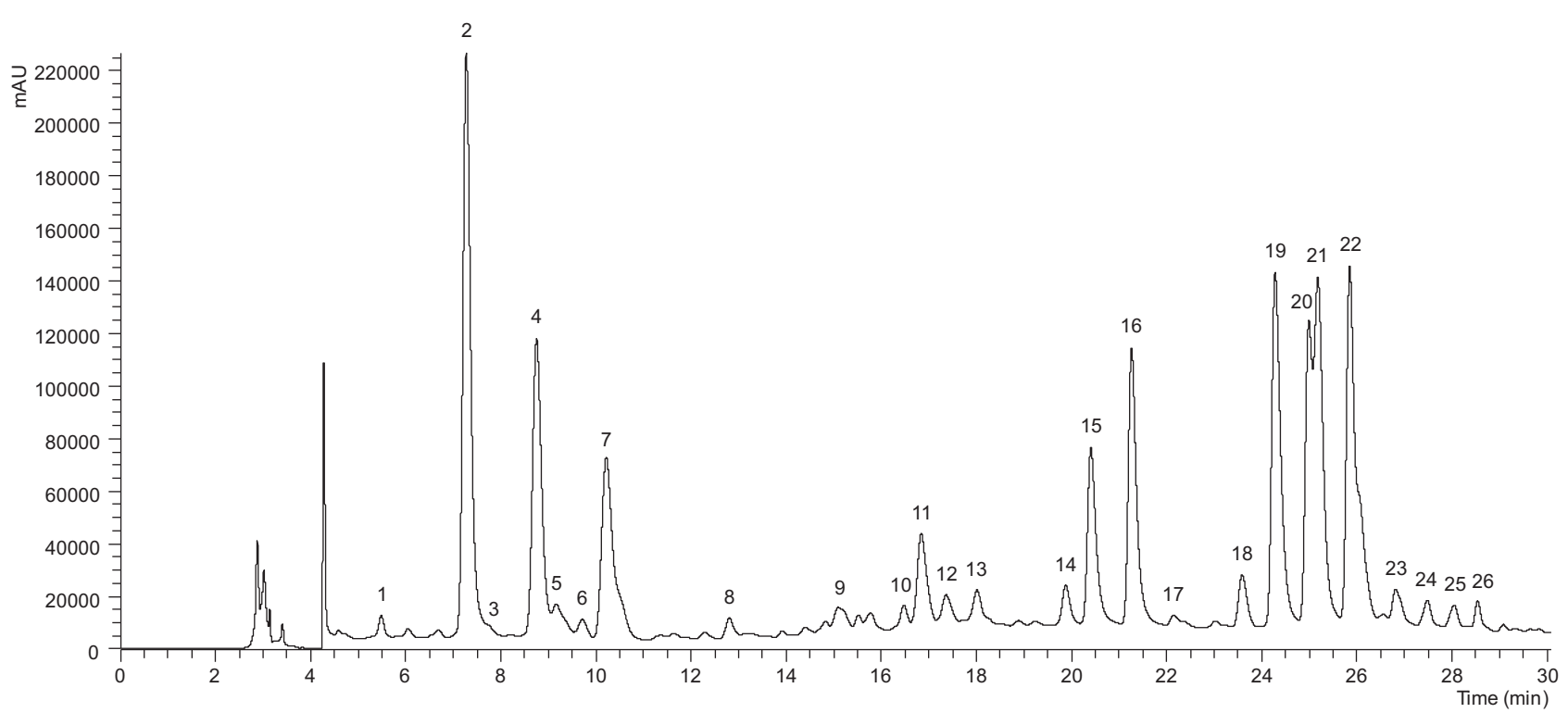

Fig. 1. HPLC profile of phenolic compounds of the non-stored fresh-cut watercress sample recorded at $370 \mathrm{~nm}$. See Table 1 for peak identification.

\subsection{Statistical analysis}

The 10 replicates of each treatment were divided into three batches, which were independently analysed in triplicate. Data were expressed as mean \pm standard deviation. All statistical tests were performed at a $5 \%$ significance level using the SPSS Statistics software (IBM SPSS Statistics for Windows, Version 22.0. Armonk, NY: IBM Corp.). The oneway analysis of variance (ANOVA) was used to assess the differences among treatments and a linear discriminant analysis (LDA) was performed to evaluate the overall effects of the different postharvest treatments on the phenolic profile of watercress. These statistical procedures were previously described by the authors (Pinela, Barreira, Barros, Antonio, et al., 2016; Pinela, Barreira, Barros, Cabo Verde, Antonio, et al., 2016a).

\section{Results and discussion}

\subsection{Characterization of phenolic compounds}

The phenolic chromatographic profile of watercress recorded at $370 \mathrm{~nm}$ is shown in Fig. 1. Compound characteristics, identities and quantitative results are presented in Tables 1 and 2. Compounds were identified based on their chromatographic, UV-vis and mass spectra characteristics. Up to twenty-six compounds were detected (Table 1), seven of which were phenolic acid derivatives, eighteen flavonoids glycoside derivatives, and one sesquiterpenoid (roseoside). Many of these compounds have already been previously reported in watercress (Martínez-Sánchez, Gil-Izquierdo, Gil, \& Ferreres, 2008; Santos et al., 2014; Spínola et al., 2016), so that their identities were assumed; in some of them the fragmentation patterns given by Martínez-Sánchez et al. (2008), Santos et al. (2014), and Spínola et al. (2016) were also used to establish the location of the substituents (e.g., peaks 4 and 8). Nonetheless, to the best of our knowledge, compounds 17 and 23-26 were not previously reported for this species. Their identities were assigned from their masses and $\mathrm{MS}^{2}$ fragments based on the compositional patterns of the previously described molecules, and assuming the presence of kaempferol as aglycon, as concluded from the fragment at $m / z 285$. Thus, compound $25\left([\mathrm{M}-\mathrm{H}]^{-}\right.$at $m / z$ 901) was assigned as kaempferol-O-hydroxyferuloylglucuronide- $O$-malonylhexoside by comparison with peak 21, although in this case bearing a hydroxyferuloylglucuronide substituent instead of hydroxyferuloylhexoside. Peaks $23\left([\mathrm{M}-\mathrm{H}]^{-}\right.$at $m / z$ 931), $24\left([\mathrm{M}-\mathrm{H}]^{-}\right.$at $\left.m / z 785\right)$ and 26
$\left([\mathrm{M}-\mathrm{H}]^{-}\right.$at $m / z$ 871) presented in their fragmentation pattern a common product ion at $m / z 623$, which can be associated to kaempferol- $O$-feruloylhexoside, and different fragments derived from the losses of feruloylhexoside (338 u), rutinoside (308 u), malonylhexoside $(248 \mathrm{u})$ or hexoside $(162 \mathrm{u})$ residues. According to the distinct losses observed in each case these compounds were identified as kaempferol$O$-feruloylhexoside- $O$-rutinoside, kaempferol-O-feruloylhexoside- $O$ hexoside and kaempferol- $O$-feruloylhexoside- $O$-malonylhexoside, respectively.

Finally, peak $17\left([\mathrm{M}-\mathrm{H}]^{-}\right.$at $m / z$ 873) was identified as quercetin$O$-dihexosyl-O-malonylhexoside. Santos et al. (2014) presented a compound with the same pseudomolecular ion, which was identified as quercetin-3-caffeolyglucoside-6"-malonylglucoside; however, the UV-vis characteristics of our compound did not present an additional shoulder with a maximum of $320 \mathrm{~nm}$, which is expected to be observed with the allocation of a caffeoyl residue. Moreover, if all the substituents are expected to be positioned on the 3-O of the aglycon, the fragment with $\mathrm{m} / \mathrm{z} 301$ should present a higher abundance.

\subsection{Effect of the postharvest treatments on the phenolic profile}

The results of the quantification of phenolic compounds in fresh (non-stored control) and minimally processed watercress stored at $4{ }^{\circ} \mathrm{C}$ for 7 days are shown in Table 2. Interestingly, the characterized profile in the minimally processed samples is not dominated by a low number of compounds, as it is often observed in plants (e.g., Koike et al. (2015a,2015b)), but most compounds are preserved in similar levels. $p$ Coumaric acid was identified as the most abundant phenolic compound in the non-stored watercress sample, followed by quercetin-3-O-sophoroside, isorhamnetin- $O$-hydroxyferuloylhexoside- $O$-hexoside, isorhamnetin- $O$-hydroxyferuloylhexoside- $O$-malonylhexoside, and isorhamnetin-O-sophoroside-O-malonylhexoside. The latter compound was also reported as being dominant in watercress juice by Spínola et al. (2016), although those authors identified caffeoylmalic acid, disinapoylgentibiose and ferulic acid as the most abundant phenolics. Grouped flavonoids predominated over phenolic acids and derivatives due to the relatively high levels of isorhamnetin and quercetin glycosides and, in lesser extent, of kaempferol. Martínez-Sánchez et al. (2008) also described high contents of quercetin and kaempferol derivatives in extract of baby-leaf watercress. Different quercetin and isorhamnetin derivatives were also identified in watercress extracts obtained by pressurized liquid extraction (Santos et al., 2014). 


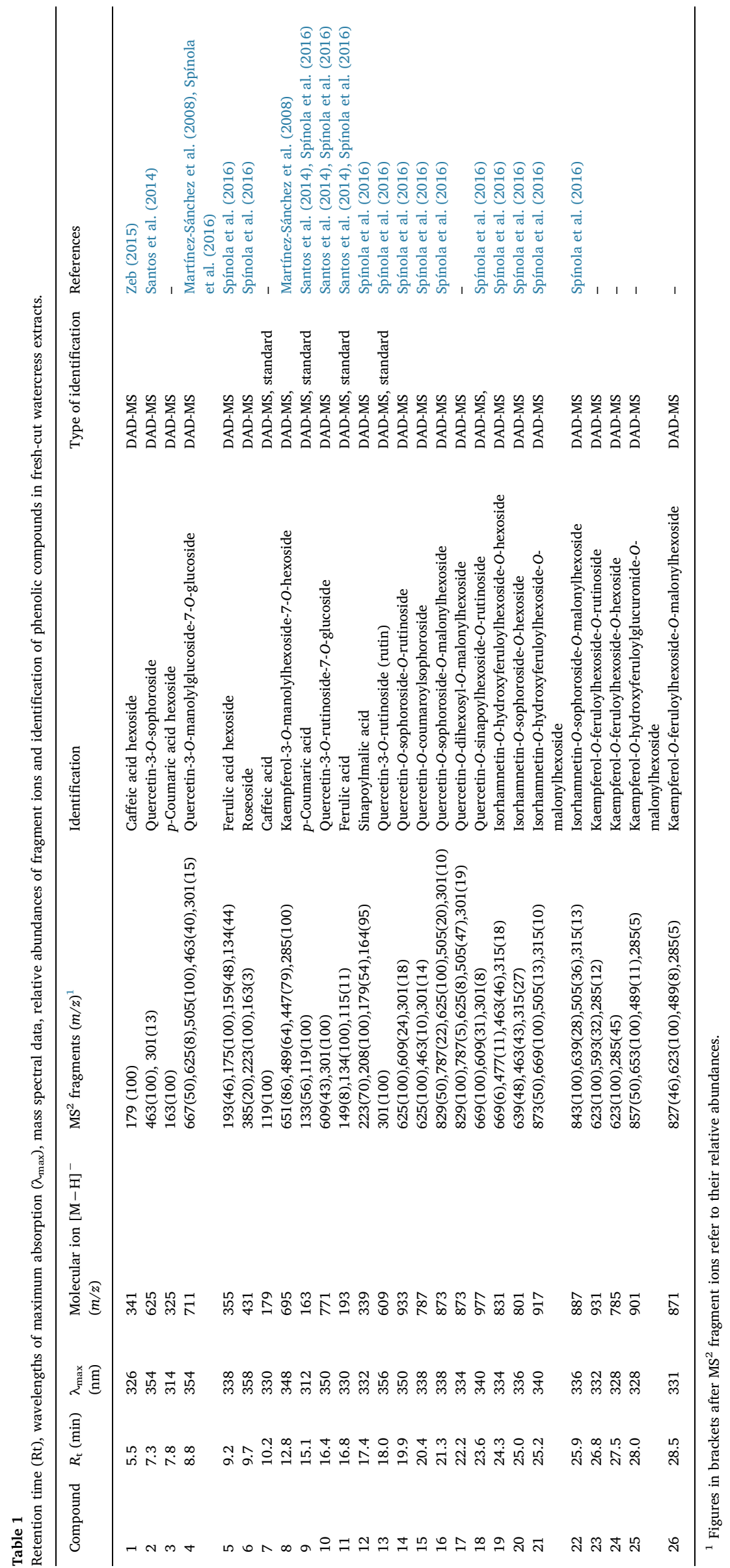




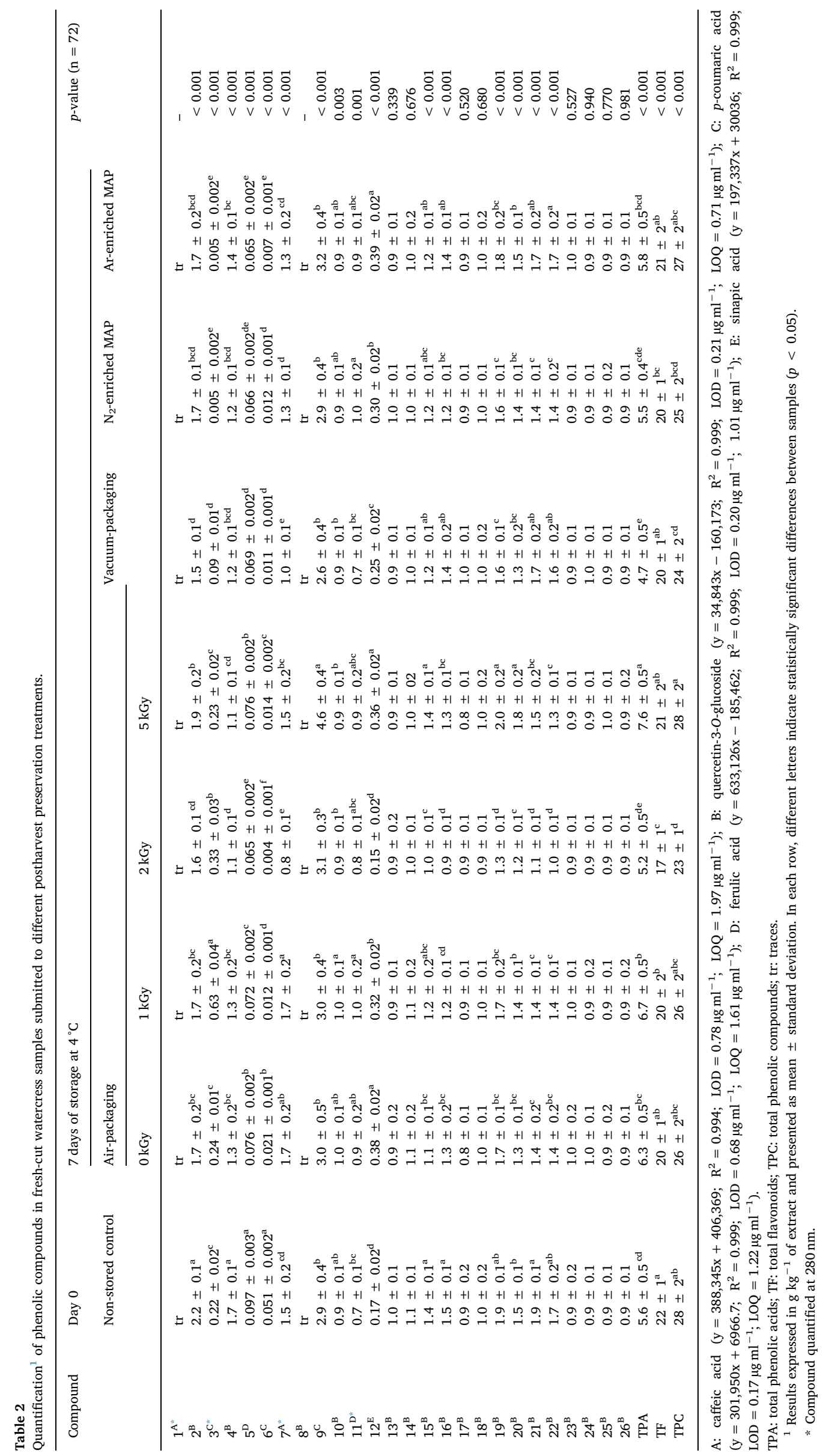


Nevertheless, besides characterizing the phenolic profile of watercress, the main purpose of this work was verifying how that profile is affected by non-thermal preservation methods, namely post-packaging $\gamma$-ray irradiation and MAP. As deduced from Table 2, most individual phenolic compounds (except some quercetin and all kaempferol derivatives) suffer minimal but statistically significant changes after 7 days of storage at $4{ }^{\circ} \mathrm{C}$, either in just refrigerated samples (air-packaging, 0 $\mathrm{KGy}$ ) or submitted to the different preservation treatment. Only in a few cases (i.e., compounds $2,4,5$ and 6 ), the levels measured in the nonstored control sample were not maintained by any of the applied postharvest treatments. In turn, the quantified levels of some phenolics (compounds 9, 10,11 and 12) were at least as high as or, in some cases, even higher than those determined in the non-stored control sample. Despite the lack of an unequivocal tendency, samples submitted to postpackaging irradiation at $5 \mathrm{kGy}$ reveal higher concentration of phenolic acids and preserved the amounts of flavonoids and total phenolic compounds, after the 7-day storage in comparison to the non-stored control. Also, higher levels of phenolic acids were also determined in the samples submitted to $1 \mathrm{kGy}$ dose. This effect induced by the low dose of $1 \mathrm{kGy}$ had already been observed in edible flowers of Viola tricolor L. (Koike et al., 2015a). By contrast, $2 \mathrm{kGy}$ had a clear deleterious effect over many of the quantified phenolic compounds. Samples stored under vacuum also revealed lower levels of grouped phenolic acids and total phenolic compounds compared to the non-stored control. However, the initial levels of grouped phenolic acids, flavonoids and total phenolic compounds did not suffer statistically significant changes when Ar-enriched MAP or just refrigeration (airpackaged non-irradiated) conditions were used. Santos et al. (2014) also found that the total phenolic content of ready-to-eat baby-leaf watercress was stable during a 10-day storage period at $3 \pm 1{ }^{\circ} \mathrm{C}$.

\subsection{Overall effects of the applied postharvest treatments on phenolic compounds}

Despite the effects induced by each postharvest treatment over individual phenolic compounds were significant in multiple occasions (Table 2), it was necessary to clarify the correlations among identified phenolic compounds and applied postharvest preservation treatments, in order to conclude the best strategy to be used in watercress preservation. Statistical classification techniques, such as linear discriminant analysis (LDA), allow comparison of all phenolic profile changes and postharvest treatment conditions simultaneously, thereby permitting finding the best possible solution.

Herein, the significant independent variables (quantified phenolic compounds) were selected by the stepwise method considering their statistically significant classification performance $(p<0.05)$, based on the Wilks' $\lambda$ test. Among the 27 entered variables ( 24 individual phenolic compounds plus grouped phenolic acids, flavonoids and total phenolic compounds), those corresponding to compounds 3 (p-coumaric acid hexoside), 4 (quercetin-3-O-malonylglucoside-7-O-glucoside), 5 (ferulic acid hexoside), 6 (roseoside), 9 (p-coumaric acid), 10 (quercetin-3-O-rutinoside-7-O-glucoside), 12 (sinapoylmalic acid), 22 (isorhamnetin- $\mathrm{O}$-sophoroside- $\mathrm{O}$-malonylhexoside) and phenolic acids group were selected as having the ability to discriminate each applied preservation treatment. These variables contributed to define seven discriminant functions, among which the first five showed statistical significance (eigenvalue higher than 1). The first three discriminant functions, which cumulatively explained $98.7 \%$ (first: $68.3 \%$; second, 26.0\%; third, 4.4\%) of the observed variance, are plotted in Fig. 2.

A clear separation of markers corresponding to the non-stored control and samples stored under different MAP or initially submitted to different $\gamma$-ray irradiation doses is noticeable. According to function 1 , which established the highest correlation with roseoside (a nonphenolic sesquiterpenoid compound), the most notorious result was the obvious separation of markers corresponding to the non-stored control sample (with significantly higher quantities of roseoside), as also

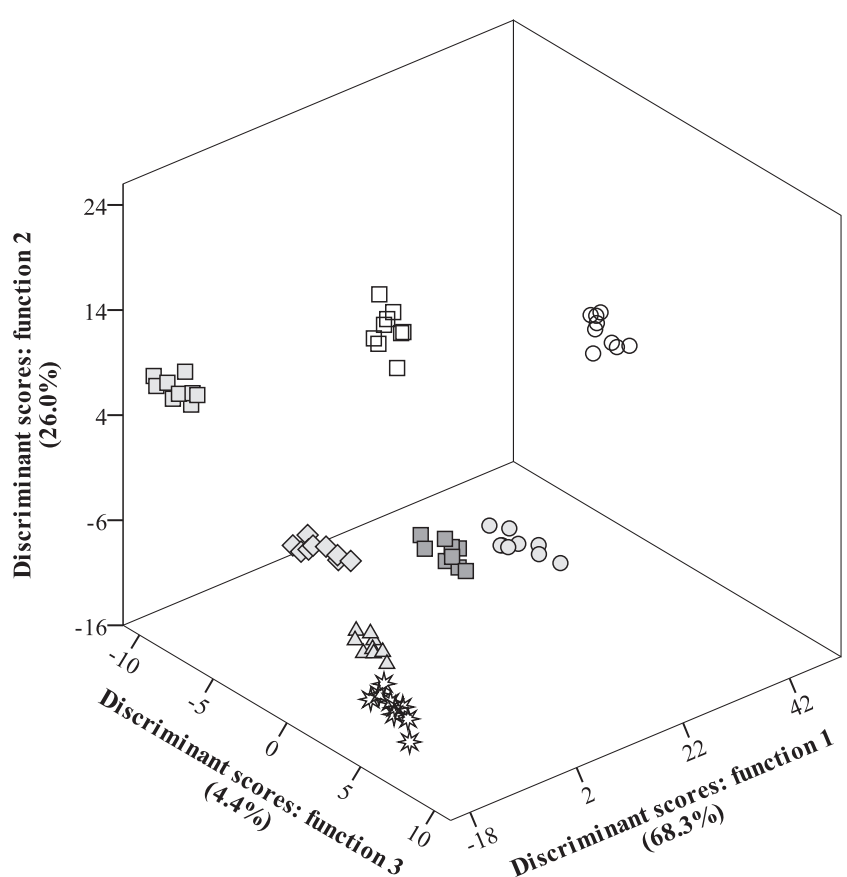

Fig. 2. 3D biplot of object scores (postharvest preservation treatments) and component loadings (quantified phenolic compounds). Non-stored control (O); non-irradiated, airpackaged control (O); 1 kGy ( $\square$ ); 2 kGy $(\square)$; 5 kGy ( $\square$ ); vacuum-packaging $(\diamond) ; \mathrm{N}_{2-}$ enriched MAP $(\triangle)$; and Ar-enriched MAP $\left(\frac{2}{2}\right)$

confirmed by the means of canonical variance (MCV) values (nonstored control: 45.341, stored control: 5.788, $1 \mathrm{kGy}$ : $-13.332,2 \mathrm{kGy}$ : -17.734 , $5 \mathrm{kGy}$ : -1.882 , vacuum-packaging: $-4.516, \mathrm{~N}_{2}$-enriched MAP: - 3.762, Ar-enriched MAP: -9.902). The markers corresponding to samples irradiated at $2 \mathrm{kGy}$ were the furthest from those corresponding to the non-stored control, thus indicating the lower roseoside content (as also showed in Table 2). This result is, therefore, a strong indicator that the variables with the highest correlations (especially roseoside) with function 1 could not be improved or maintained by any of the applied treatments. Nevertheless, among all postharvest treatments, the non-irradiated stored control in conventional atmosphere was the most efficient in preserving the roseoside contents, followed by the $5 \mathrm{kGy}$ dose. Function 2, on the other hand, was particularly effective in separating samples stored under MAP and those irradiated at $1 \mathrm{kGy}$ (MCV, non-stored control: 4.715, stored control: 0.013, $1 \mathrm{kGy:} 22.919$, 2 kGy: 7.532, 5 kGy: -0.896 , vacuum-packaging: $-6.515, \mathrm{~N}_{2}$-enriched MAP: - 13.162, Ar-enriched MAP: - 14.606), especially due to differences in p-coumaric acid hexoside contents (lower values in MAP samples and particularly high in samples irradiated at $1 \mathrm{kGy}$, followed by those irradiated at $2 \mathrm{kGy}$ ). Likewise, this indicates that all compounds more related to function 2 (with special relevance to $p$-coumaric acid hexoside) were specially favoured in samples irradiated at a $1 \mathrm{kGy}$ dose. Finally, function 3 was not particularly effective in separating any of the assayed samples, which is in line with the lower percentage of explained variation (4.4\%). Nevertheless, this function contributed to increase the resolution of sample clusters separated by functions 1 and 2. In terms of classification performance, all samples were correctly classified, either for original grouped cases, as well as for cross-validated ones. Therefore, based on Fig. 2, it can be concluded that simple packaging is suitable for preserving the phenolic profile of watercress during refrigerated storage.

The effects of post-packaging $\gamma$-ray irradiation (Pinela, Barreira, Barros, Cabo Verde, Antonio, et al., 2016a) and inert gas-enriched MAP (Pinela, Barreira, Barros, Antonio, et al., 2016) on relevant quality attributes of fresh-cut watercress were evaluated in previous studies, which demonstrated that Ar was an appropriate gas and $2 \mathrm{kGy}$ a suitable dose for preserving the overall postharvest quality of this 
vegetable during refrigerated storage. It was also reported that the $5 \mathrm{kGy}$ dose originated a final product with enhanced health-promoting properties, characterized by an interesting antioxidant activity and levels of linoleic and $\alpha$-linolenic acids, monounsaturated fatty acids such as oleic acid, total tocopherols and total phenolic compounds. Interestingly, in the present study, the same irradiation dose better preserved or led to an increase in the contents of some individual phenolic compounds, namely quercetin-3-O-sophoroside, $p$-coumaric acid, quercetin-O-coumaroylsophoroside, isorhamnetin- $O$-hydroxyferuloylhexoside- $O$-hexoside and isorhamnetin- $O$-sophoroside- $O$ hexoside, as also of grouped phenolic acids and total phenolic compounds. Therefore, these results support the previous findings regarding the suitability of irradiating at $5 \mathrm{kGy}$ to promote the watercress phenolic content.

\subsection{Correlation between phenolic compounds and antioxidant activity}

Based on the Pearson correlation coefficients $(R)$ presented in Table S.1, it was concluded that total flavonoids were strongly correlated to the DPPH free-radical scavenging activity and $\beta$-carotene bleaching inhibition capacity of the watercress extracts (antioxidant activity data previously reported by Pinela, Barreira, Barros, Antonio, et al. (2016) and Pinela, Barreira, Barros, Cabo Verde, Antonio, et al. (2016a), while total phenolic compounds were found strongly and moderately correlated, respectively. Quercetin-derived compounds 15 and 18 were strongly correlated with the DPPH free-radical scavenging activity, while compounds 16, 17 (quercetin derivatives) and 21 (an isorhamnetin derivative) were found strongly correlated with the $\beta$-carotene bleaching inhibition capacity. All these correlations were negative, but the antioxidant activity results were expressed in $\mathrm{EC}_{50}$ values, and the lower the $\mathrm{EC}_{50}$ value the higher the antioxidant capacity of the extract. Furthermore, since most of these compounds were modulated by the applied postharvest treatments (Table 2), the antioxidant activity will also change as a function of the applied treatment.

These results are consistent with those of Agudelo, Barros, SantosBuelga, Martínez-Navarrete and Ferreira (2017) who showed that flavonoids were highly correlated with the DPPH free-radical scavenging activity and $\beta$-carotene bleaching inhibition capacity of grapefruit (Citrus paradisi var. Star Ruby) hydromethanolic extracts. M'rabet et al. (2017) also showed that flavonoids (namely quercetin-3-O-neohesperidoside, rutin, kaempferol-3-O-rutinoside and kaempferol-O-dihexoside) were the main contributors to the DPPH free-radical scavenging activity of Melia azedarach L. extracts. It has been demonstrated that the scavenging activity of flavonoids is influenced by their chemical structure, including the degree of hydroxylation and their positions, and glycosylation status (Farsad \& Alizadeh, 2017). On the other hand, the low contribution of phenolic acids to the antioxidant activity of $M$. azedarach was related to the presence of glycosyl moieties in their structures, which can mask their functional groups (M'rabet et al., 2017).

\section{Conclusions}

As far as we know, this is the first report on the effects of post-packaging $\gamma$-ray irradiation and MAP, on the phenolic profile of watercress. $p$ Coumaric acid was identified as the most abundant phenolic compound in watercress, although the group of flavonoids predominated over phenolic acids. Four kaempferol derivatives (kaempferol-O-rutinoside- $O$-feruloylhexoside, kaempferol-O-feruloylhexoside-O-hexoside, kaempferol-Ohydroxyferuloylglucuronide-O-malonylhexoside and kaempferol-O-feruloylhexoside-O-malonylhexoside) were identified for the first time in this cruciferous vegetable. Samples stored under vacuum and irradiated at $2 \mathrm{kGy}$ revealed a lower phenolic content due to a decrease in both total phenolic acids and flavonoids. Ar-enriched MAP and simple refrigeration at $4^{\circ} \mathrm{C}$ preserved the initial phenolic content well, while irradiation at $5 \mathrm{kGy}$ increased the concentrations of phenolic acids, also maintaining those of flavonoids and total phenolic compounds. Moreover, flavonoids were found to be strongly correlated to DPPH free-radical scavenging activity and $\beta$-carotene bleaching inhibition capacity.

\section{Acknowledgments}

The authors are grateful to PRODER research project no. 53514, AROMAP, for financial support of the work; to the Foundation for Science and Technology (FCT) of Portugal and FEDER, under Programme PT2020, for financial support to CIMO (UID/AGR/00690/ 2013); to FCT/MEC for financial support to REQUIMTE/LAQV (UID/ QUI/50006/2013 - POCI/01/0145/FERDER/007265); and to FCT for the grants attributed to J. Pinela (SFRH/BD/92994/2013; funded by the European Social Fund and MEC through Programa Operacional Capital Humano (POCH)), L. Barros and J. Barreira contracts. The authors are also grateful to the Interreg España-Portugal for financial support through the project 0377_Iberphenol_6_E. We would also like to thank Dr. Sandra Cabo Verde and Prof. Amilcar L. Antonio, for $\gamma$-ray irradiation (C2TN in Bobadela, Lisbon, Portugal) of the samples as described in https://doi.org/10.1016/j.foodchem.2016.03.050.

\section{Appendix A. Supplementary data}

Supplementary data associated with this article can be found, in the online version, at http://dx.doi.org/10.1016/j.foodchem.2018.01.181.

\section{References}

Agudelo, C., Barros, L., Santos-Buelga, C., Martínez-Navarrete, N., \& Ferreira, I. C. F. R. (2017). Phytochemical content and antioxidant activity of grapefruit (Star Ruby): A comparison between fresh freeze-dried fruits and different powder formulations. LWT - Food Science and Technology, 80, 106-112.

Barkai-Golan, R., \& Follett, P. A. (2017). Safety of fresh and fresh-cut fruits and vegetables following irradiation. In R. Barkai-Golan, \& P. A. Follett (Eds.). Irradiation for quality improvement, microbial safety and phytosanitation of fresh produce (pp. 129-156). Academic Press.

Baselice, A., Colantuoni, F., Lass, D. A., Nardone, G., \& Stasi, A. (2017). Trends in EU consumers' attitude towards fresh-cut fruit and vegetables. Food Quality and Preference, 59, 87-96.

Bessada, S. M. F., Barreira, J. C. M., Barros, L., Ferreira, I. C. F. R., \& Oliveira, M. B. P. P. (2016). Phenolic profile and antioxidant activity of Coleostephus myconis (L.) Rchb.f.: An underexploited and highly disseminated species. Industrial Crops and Products, 89, $45-51$.

Boeing, H., Bechthold, A., Bub, A., Ellinger, S., Haller, D., Kroke, A., ... Watzl, B. (2012). Critical review: Vegetables and fruit in the prevention of chronic diseases. European Journal of Nutrition, 51(6), 637-663.

Boyd, L. A., McCann, M. J., Hashim, Y., Bennett, R. N., Gill, C. I. R., \& Rowland, I. R. (2006). Assessment of the anti-genotoxic, anti-proliferative, and anti-metastatic potential of crude watercress extract in human colon cancer cells. Nutrition and Cancer, 55(2), 232-241.

Carvalho, A. M., \& Morales, R. (2013). Persistence of wild food and wild medicinal plant knowledge in a Northeastern region of Portugal. In A. P. Pardo de Santayana, \& R. Puri (Eds.). Ethnobotany in the New Europe: People, Health and Wild Plant Resources (pp. 147-171). Oxford, UK: Berghahn Books.

Farsad, N. A., \& Alizadeh, M. (2017). Antioxidant properties of the flavonoid fisetin: An updated review of in vivo and in vitro studies. Trends in Food Science \& Technology, 70, 34-44.

Fernando Reyes, L., Emilio Villarreal, J., \& Cisneros-Zevallos, L. (2007). The increase in antioxidant capacity after wounding depends on the type of fruit or vegetable tissue. Food Chemistry, 101(3), 1254-1262.

Francis, G. A., Gallone, A., Nychas, G. J., Sofos, J. N., Colelli, G., Amodio, M. L., \& Spano, G. (2012). Factors affecting quality and safety of fresh-cut produce. Critical Reviews in Food Science and Nutrition, 52(7), 595-610.

Gill, C. I. R., Haldar, S., Boyd, L. A., Bennett, R., Whiteford, J., Butler, M., ... Rowland, I. R. (2007). Watercress supplementation in diet reduces lymphocyte DNA damage and alters blood antioxidant status in healthy adults. American Journal of Clinical Nutrition, 85(2), 504-510.

Han, C., Ji, Y., Li, M., Li, X., Jin, P., \& Zheng, Y. (2016). Influence of wounding intensity and storage temperature on quality and antioxidant activity of fresh-cut Welsh onions. Scientia Horticulturae, 212, 203-209.

Kacjan Marsić, N., Sircelj, H., \& Kastelec, D. (2010). Lipophilic antioxidants and some carpometric characteristics of fruits of ten processing tomato varieties, grown in different climatic conditions. Journal of Agricultural and Food Chemistry, 58, 390-397.

Koike, A., Barreira, J. C. M., Barros, L., Santos-Buelga, C., Villavicencio, A. L. C. H., \& Ferreira, I. C. F. R. (2015a). Edible flowers of Viola tricolor L. as a new functional food: Antioxidant activity, individual phenolics and effects of gamma and electronbeam irradiation. Food Chemistry, 179, 6-14. 
Koike, A., Barreira, J. C. M., Barros, L., Santos-Buelga, C., Villavicencio, A. L. C. H., \& Ferreira, I. C. F. R. (2015b). Irradiation as a novel approach to improve quality of Tropaeolum majus L. flowers: Benefits in phenolic profiles and antioxidant activity. Innovative Food Science \& Emerging Technologies, 30, 138-144.

M'rabet, Y., Rokbeni, N., Cluzet, S., Boulila, A., Richard, T., Krisa, S., Marzouki, L., Casabianca, H., \& Hosni, K. (2017). Profiling of phenolic compounds and antioxidant activity of Melia azedarach L. leaves and fruits at two stages of maturity. Industrial Crops and Products, 107, 232-243.

Ma, L., Zhang, M., Bhandari, B., \& Gao, Z. (2017). Recent developments in novel shelf life extension technologies of fresh-cut fruits and vegetables. Trends in Food Science \& Technology, 64, 23-38.

Martínez-Sánchez, A., Gil-Izquierdo, A., Gil, M. I., \& Ferreres, F. (2008). A comparative study of flavonoid compounds, vitamin C, and antioxidant properties of baby leaf Brassicaceae species. Journal of Agricultural and Food Chemistry, 56(7), 2330-2340.

Pinela, J., Barreira, J. C. M., Barros, L., Antonio, A. L., Carvalho, A. M., Oliveira, M. B. P. P., \& Ferreira, I. C. F. R. (2016). Postharvest quality changes in fresh-cut watercress stored under conventional and inert gas-enriched modified atmosphere packaging. Postharvest Biology and Technology, 112, 55-63.

Pinela, J., Barreira, J. C. M., Barros, L., Cabo Verde, S., Antonio, A. L., Carvalho, A. M., ... Ferreira, I. C. F. R. (2016a). Suitability of gamma irradiation for preserving fresh-cut watercress quality during cold storage. Food Chemistry, 206, 50-58.

Pinela, J., Barreira, J. C. M., Barros, L., Cabo Verde, S., Antonio, A. L., Oliveira, M. B. P. P., ... Ferreira, I. C. F. R. (2016b). Modified atmosphere packaging and post-packaging irradiation of Rumex induratus leaves: A comparative study of postharves quality changes. Journal of Food Science and Technology, 53(7), 2943-2956.
Pinela, J., \& Ferreira, I. C. F. R. (2017). Nonthermal physical technologies to decontaminate and extend the shelf-life of fruits and vegetables: Trends aiming at quality and safety. Critical Reviews in Food Science and Nutrition, 57(10), 2095-2111.

Ravasco, P., João, D., Jorge, M., Rowland, I., Giallourou, N., Swann, J., ... Harbourne, N. (2015a). MON-LB027: Watercress in breast cancer patients undergoing radiotherapy: Relevance in DNA damage of dermatitis? Clinical Nutrition, 34, S260-S261.

Ravasco, P., João, D. R., Rowland, I., Giallourou, N., Swann, J., Dias, L. M., ... Harbourne, N. (2015b). MON-LB019: Does watercress influence phase angle in breast cancer patients during radiotherapy? Clinical Nutrition, 34, S257.

Sandhya (2010). Modified atmosphere packaging of fresh produce: Current status and future needs. LWT - Food Science and Technology, 43(3), 381-392.

Santos, J., Oliveira, M. B. P. P., Ibáñez, E., \& Herrero, M. (2014). Phenolic profile evolution of different ready-to-eat baby-leaf vegetables during storage. Journal of Chromatography A, 1327, 118-131.

Silveira, A. C., Araneda, C., Hinojosa, A., \& Escalona, V. H. (2014). Effect of non-conventional modified atmosphere packaging on fresh cut watercress (Nasturtium officinale R. Br.) quality. Postharvest Biology and Technology, 92, 114-120.

Spínola, V., Pinto, J., \& Castilho, P. C. (2016). In vitro studies on the effect of watercress juice on digestive enzymes relevant to type 2 diabetes and obesity and antioxidant activity. Journal of Food Biochemistry, 41(1), e12335.

Vilela, C., Santos, S. A. O., Villaverde, J. J., Oliveira, L., Nunes, A., Cordeiro, M., ... Silvestre, A. J. D. (2014). Lipophilic phytochemicals from banana fruits of several Musa species. Food Chemistry, 162, 247-252.

Zeb, A. (2015). Phenolic profile and antioxidant potential of wild watercress (Nasturtium officinale). SpringerPlus, 4(1), 714. 